\title{
The Lost Generation
}

"Barefoot Doctors" in Post-reform China

Jiong Tu

\section{(2) OpenEdition}

\section{Journals}

Electronic version

URL: http://journals.openedition.org/chinaperspectives/7084

ISSN: 1996-4617

\section{Publisher}

Centre d'étude français sur la Chine contemporaine

\section{Printed version}

Date of publication: 1 December 2016

Number of pages: 7-17

ISSN: 2070-3449

\section{Electronic reference}

Jiong Tu, «The Lost Generation », China Perspectives [Online], 2016/4 | 2016, Online since 01

December 2016, connection on 28 October 2019. URL : http://journals.openedition.org/

chinaperspectives/7084

(C) All rights reserved 


\title{
The Lost Generation
}

\author{
"Barefoot Doctors" in Post-reform China
}

\begin{abstract}
In the 1960s and 1970s, China's barefoot doctor system was acclaimed worldwide for providing inexpensive and equally accessible medical care for rural populations. In the 1980s, with the advent of market reform, the barefoot doctor system came to an end. Many barefoot doctors either became private doctors or gave up medical practice. More than three decades have passed since this dramatic change, and barefoot doctors seem to have been forgotten. However, the legacy of the barefoot doctor system is still felt in the hardship of aging former barefoot doctors who now find themselves pensionless. Based on ethnographic research in a county in Sichuan Province from 2011 to 2012, this article explores the experience of a group of former barefoot doctors to observe their transition in post-reform China, and their struggle for payment, pension, and status in recent years. It records the change these doctors experienced from barefoot doctors working under very difficult conditions in the collective era, to individual doctors in the market era who struggle with qualification requirements, market competition, and selfsupport, to the newly ambiguous status of village doctors, who constitute an important part of the primary health care network but are still marginalised in the health care system.
\end{abstract}

KEYWORDS: barefoot doctors, payment, pension, health care, rural China.

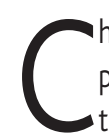
hina's barefoot doctor system is known for having provided inexpensive and accessible medical care to its large rural population in the 1960s and 70s. (1) Barefoot doctors, chosen from local farmers, received basic medical training and then served in the rural areas with a focus on preventive and primary health care. The barefoot doctor system together with the Cooperative Medical System (CMS) in the rural areas became a model for the developing world, reflecting an approach to health care that was "egalitarian, grassroots-based, decentralised, de-professionalised, 'low-tech,' economically feasible, and culturally appropriate." (2) However, the system came to an end with the advent of market reforms in the 1980s, and many barefoot doctors either became private doctors or gave up medical practice. In 1985, the name "barefoot doctor" (chijiao yisheng) was officially abolished and replaced by the name "village doctor" (xiangcun yisheng). (3) More than three decades have passed since this dramatic change, and barefoot doctors seem to have been forgotten. However, the legacy of the barefoot doctor system is still felt in the hardships of aging former barefoot doctors who now find themselves pensionless. It is estimated that approximately 1.5 million people ${ }^{(4)}$ worked as barefoot doctors in the collective era, and today there are still around one million ${ }^{(5)}$ former barefoot doctors nationwide. Based on a case study in Riverside County, this article records the experiences of a group of former barefoot doctors, showing how they strive for payment, pension, and status in post-reform China, and how the historical experience of barefoot doctors can inspire health care reforms today.

The study is based on one year of ethnographic research in Riverside County (pseudonym) of Sichuan Province between October 2011 and October 2012. In early 2012, my acquaintance introduced me to a village doctor - Doctor Lian from Revival Town, who was in his 60s. I visited Doctor Lian and interviewed him and two more village doctors he introduced to me. The next morning, I got a phone call from another village doctor in the same town, who had heard of my visit and wanted me to visit him as well.
"I have a lot to say," he stated on the phone. I went to Revival Town again and met Doctor Li, a 76-year-old former barefoot doctor. A few days later, another doctor from Revival Town called me and said that a group of them would be gathering for a meeting in the township hospital and would like to meet me afterwards to "express their thoughts." I subsequently met Doctor Zhao and around 10 other village doctors who were in their 50s, 60s, and 70s. All these doctors were former barefoot doctors who continued medical practice after their collective medical teams were dismantled. In my field, this group of former barefoot doctors appeared to be one of the most resentful groups in the on-going health care reform. After these encounters, I visited 16 village clinics and 12 private clinics around the county, meeting dozens of former barefoot doctors. I interviewed these doctors in

1. The program started from the 1960 s and became internationally influential in the 1970 s. The system was acknowledged by the WHO for securing people's basic health care rights and was a major inspiration to the primary health care movement, leading up to the Alma-Ata Conference in 1978. See Cui Weiyuan, "China's Village Doctors Take Great Strides," Bulletin of the World Health Organisation, Vol. 86, No. 12, 2008, pp. 914-915; Peter Worsley, "Non-Western Medical Systems," Annual Review of Anthropology, Vol. 11, 1982, pp. 349-375.

2. Wang Shaoguang, "China's Double Movement in Health Care," in Leo Panitch and Colin Leys (eds), Socialist Register 2010: Morbid Symptoms: Health under Capitalism, The Merlin Press, 2010, pp. 240-261.

3. See Editorial, "Buzai shiyong 'chijiao yisheng' mingcheng, gonggu fazhan xiangcun yisheng duiwu" (Aborting the title "barefoot doctor," fortifying the development of rural doctors), Renmin ribao (People's Daily), 25 January 1985. In the post-reform era, although many former barefoot doctors have become village doctors, other people (such as new practitioners who graduated from local medical schools) have also joined the village doctor group. Village doctors are therefore not a homogeneous group.

4. Cao Pu, "Renmin gongshe shiqi de nongcun hezuo yiliao zhidu" (The Rural Cooperative Medical System during the time of the People's Commune), Zhonggong zhongyang dangjiao xuebao (Journal of the Party School of the Central Committee of the CPC),Vol. 13, No. 6, 2009, pp. 78-83. Also see Xinhua News, "Xiangcun yisheng de laiyuan he zuoyong" (The sources and contributions of village doctors), 18 August 2003, http://news.xinhuanet.com/zhengfu/2003-08/18/content_ 1030667.htm (accessed on 4 May 2014)

5. The figure of one million came from various estimates and was checked through interviews and Internet searches. However, there are no official figures on the actual number of former "barefoot doctors" who are still alive. 
groups or individually. All the interviews were written down the same day. I read the interview materials and field notes several times, jotting down thematic topics and issues that came up repeatedly. The accounts are based on these doctors' personal experiences, stories, and interpretations of their current situation. In the years following the fieldwork, I kept in contact with some of these doctors, following their recent situation. This article focuses on the transformation of this group of former barefoot doctors, who started medical practice in the collective era and continued medical practice after market reform.

\section{Barefoot doctors in transition}

\section{A letter from a group of barefoot doctors}

In the field, I collected several autobiographies and petition letters from former barefoot doctors, who eagerly wrote down their life stories. The petition letter to the government penned by 36 barefoot doctors in Revival Town is a telling example that summarises barefoot doctors' life histories, experiences, and expectations.

\section{Healing the Wounded and Rescuing the Dying for Forty Years, Barefoot Doctors Look for the Party's Grace}

We are a group of village doctors in the poor mountain area of $x x$. After more than twenty years' silence, today we recount the hard years we have gone through. The past is turbulent like songs and pictures; it shows the transformation over different eras, and tells the hardship of barefoot doctors over the past thirty to forty years... In the 1960s, in implementing the party's "6.26 guidance" - "putting the focus of medical work into the rural areas," the country began to set up its rural collective medical institutions. In our locality, the [Communist] Party and the government also chose some excellent medical professionals. We were trained for two years in professional skills and took the responsibility of setting up the rural collective medical system, which basically solved issues involving the lack of medical facilities and the difficulty in seeking health care in the rural areas. In the 70s, targeting peasants' low health consciousness and poor health care conditions, [we] on the one hand promoted the patriotic health and hygienic movement (aiguo weisheng yundong) among the peasants and on the other hand combined Western and indigenous measures [to treat patients], planting and collecting herbs by ourselves. By using "one silver needle and a handful of herbs" (yigenzhen, yibacao), [we] resolved the shortage of medicine, ensuring the health of the masses. Later, with the rapid increase of the population, [we] took up family planning propaganda, carried out birth surveillance and control, and performed ligations and abortions, etc. In the 80s, with the progress of science and technology, most barefoot doctors went to county medical school to continue their studies, gaining a diploma of Secondary Vocational Education and a Village Doctor Certificate. We continually explored new medical technology, put new knowledge into practice, and improved our medical skills. Through assessments and tests, most village doctors later became [licenced] physicians or assistant physicians, and were responsible for health care work and the prevention of infectious diseases in the rural areas. In the 90s, village doctors were charged various onerous fees and experienced great difficulty in medical practice, but [we] still upheld our responsibility by monitoring epidemics, delivering vaccinations, and promoting health care.

In 2003, SARS broke out nationwide. People felt at risk and panicked. Migrant workers returned to their villages, one after the other. This epidemic gained the attention of party and state leaders, and the government carried out emergency mobilisation. With one order [from above], we village doctors took on the responsibility of fighting the invisible SARS war without any protection.

(...)

In the past 30 to 40 years, in order to promote people's health, we village doctors have walked from village to village, from household to household, whether in rainy or windy weather, whether in hot summers or frozen winters, and regardless of how far we had to walk in darkness or on mountainous roads. We always served at the bottom of the three-tiered health network, visiting our peasant brothers whenever they called. We contributed innumerable efforts and saved countless lives. Villagers praised us as "family doctors" and "caring doctors."

In our 30 to 40 years of hard work, we contributed our youth and our whole lives to the party, to the state's health care work, and to the health of the peasant masses. Now we are old with white hair, but the reform wave has washed us into a "forgotten corner," which makes us [sad]... Our brother village teachers began to be treated like civil servants, and recently village veterinarians have also received pensions. We barefoot doctors have contributed so much to the country and the people, and have experienced so many hardships. We have never asked anything from the government as long as we could sustain ourselves. However, now most of us are old and sick, and we feel disappointed and depressed, lonely and desolate. Driven to despair, now we can only speak to the party and the state... We really hope the party and the government consider the village doctors' pension issue, and let village doctors enjoy the same entitlements as village teachers. We hope the party and the government allow us weary village doctors to feel the warmth of the state after decades of work, and realise [the official slogan that] "the old have support, the sick get care," allowing us to live without worries [about subsistence in old age], and consoling our broken hearts.

The letter above shows how former barefoot doctors narrate and perceive themselves and the changes around them. It states the origin of the "barefoot doctor" system. On 26 June 1965, hearing the report of the Minister of Health, Mao was angered by the huge disparity between rural and urban healthcare conditions and gave a talk asking the Ministry of Health to "put the medical focus on the rural areas." The talk, referred to as the "6.26 Guidance" or "June 26 Speech," became the guiding principle for health care work in the years that followed. From then on, the training of health professionals to meet health care needs in the rural areas became a priority. Many paramedical workers were trained to handle the most basic health care in the rural areas. Some of them replaced qualified medical practitioners and were called "barefoot doctors." The training of these barefoot doctors and primary health workers was much shorter than regular medical training. Usually they started with an initial course of several months covering rudimentary and preventive medical care, followed by in-service training, which might be achieved by working with a qualified doctor in the countryside, by secondment to a hospital, or by taking courses arranged by a teaching hos- 
pital. (6) In Riverside County, the training of rural health professionals combined school/hospital education and traditional master-apprentice training. Most local health professionals had already received some traditional medical training from their families or elderly doctors before enrolling in schools or hospital courses. Barefoot doctors were chosen among these half-trained persons with a politically sound family background, (7) who were briefly educated again in local medical schools or hospitals for preventive and Western medical knowledge and then returned to work in their villages. During and after the Cultural Revolution, large numbers of paramedical workers were trained in Riverside County, including 1,868 barefoot doctors and 4,880 primary health workers by 1977. ${ }^{(8)}$ Nationwide, there were about 1.5 million people working as barefoot doctors by $1975,{ }^{(9)}$ covering $90 \%$ of Chinese villages. ${ }^{(10)}$ These barefoot doctors, together with other health workers in the rural areas, ${ }^{(11)}$ constituted the bottom of the three-tiered (county-commune-brigade) primary healthcare network. Largely due to the primary health care provided by these health professionals, health conditions in rural China improved dramatically during this period, with reduced infectious disease, ${ }^{(12)}$ lower infant mortality rates, ${ }^{(13)}$ and increased life expectancy. ${ }^{(14)}$ Considering the social and political context of "barefoot doctors" - the internal turmoil, political chaos, and stunted socioeconomic development during the Cultural Revolution from 1966 to 1976 - the achievement of the barefoot doctor system is even more remarkable. ${ }^{(15)}$

Barefoot doctors took on multiple roles in the rural community: first, they were peasants who lived in the village and took part in farm work; second, they were doctors, treating illness and relieving pain for villagers; third, they represented the state in promoting health and implementing health policies such as birth control and vaccination. In the process, barefoot doctors served as a bridge between the state and rural society. Scholars regard the barefoot doctor movement as an "attempt by the state to reach out to peasants by offering affordable care", ${ }^{(16)}$ as part of the state-driven project of medical modernisation that effectively expanded the state medical system to the rural areas. (17) The barefoot doctor system was not without its problems, but together with the CMS, it enabled farmers to support themselves collectively in obtaining basic health care in a rural-urban segregated society.

The emergence of "barefoot doctors" was supported by Mao as a social and political task. Its emergence at the height of the Cultural Revolution in 1968 reflected the political ideology of egalitarianism and the rural development strategies of the Cultural Revolution. Yet, as the political fever waned, the Cultural Revolution and the collective production system were criticised in the late 1970s, and the rural CMS and barefoot doctor system also came under attack. Since the 1980s, when China adopted market reform, its health system has also experienced a transition from a state/collective-run and financed system toward more private financing and delivery of health care. The medical work focus has shifted from primary and community health care to curative and high-tech work in the government's effort to modernise the country. Barefoot doctors and collective clinics in the rural areas began to be neglected.

\section{The "disappeared" collective clinics}

Doctor Wei, Doctor Li, Doctor Lian, and another doctor worked in the same medical team as barefoot doctors in the 1970s. In Riverside County, the collective production system was replaced by the household production system in 1981. Rural economic reform led to the dismantling of the communes - the collectives in charge of organising and managing rural healthcare work. The collective clinics supported by the collective production system and the commune became unsustainable. The four doctors then formed a collective clinic by paying an annual fee to the village, and financed themselves by charging patients privately. This tentative collaboration lasted only a few years. Without funding from the collective production system or support from the commune, the clinic's business could not sustain the livelihood of the four doctors. Later, Doctor Li left the medical team and opened his own clinic in town, focusing on orthopaedics. Doctor Lian opened a clinic in his village, working part-time as a village doctor while engaging in some other businesses to sustain his family. Doctor Wei and his son held the collective clinic licence, but moved the clinic to the town, making it a de facto private clinic. The other doctor changed his profession and became a teacher in the local primary school. Although the collective medical team licence continued under the name of the four doctors, the clinic had already disappeared in the 1980s.

Doctor Zhao from Revival Town experienced a similar fate. In the collective era, the medical team of his production brigade had three barefoot doctors. They performed outstandingly and were named the "advanced/model medical team" (xianjin yiliaozu). In the post-reform era, one of the doctors joined the township hospital in the 1980s, and another old doctor died in the 1990s. Doctor Zhao thus operated the old clinic alone as a village doctor.

6. Penny Kane, "An Assessment of China's Health Care," The Australian Journal of Chinese Affairs, No. 11, 1984, pp. 1-24.

7. Priority was given to villagers from poor and middle-peasant families, while those coming from rich peasant families or with a counterrevolutionary family background were excluded from becoming barefoot doctors or needed to undergo strict scrutiny.

8. Riverside xianzhi (Gazetteer of Riverside County), Riverside, Riverside County Chorography Editing Committee, 1990.

9. Cao Pu, "Renmin gongshe shiqi de nongcun hezuo yiliao zhidu" (The Rural Cooperative Medical System during the time of the People's Commune), art. cit.

10. See Xinhua News, "Xiangcun yisheng de laiyuan he zuoyong" (The sources and contributions of village doctors), 18 August 2003, http://news.xinhuanet.com/zhengfu/2003-08/18/content_ 1030667.htm (accessed on 4 May 2014). Li's research also showed that at the time of his research, there were already about one million barefoot doctors, or 1 per 800 in the population, and the number was increasing since the target was one barefoot doctor per 500 population. Li Haihong, "Chijiaoyisheng" yu Zhongguo xiangtu shehui yanjiu: yi Henansheng weili (Research on "Barefoot Doctors" and Chinese Rural Society: Taking Henan Province as an example), Beijing, Social Sciences Academic Press, 2015.

11. It is estimated that an additional 3.7 million health workers served rural China in 1970. Judith Banister, China's Changing Population, Stanford, Stanford University Press, 1987.

12. Vikki Valentine, "Health for the Masses: China's 'Barefoot Doctors'," NPR, 4 November 2005, www.npr.org/templates/story/story.php?storyld=4990242 (accessed on 1 May 2016).

13. Cedric Howshan Bien, The Barefoot Doctors: China's Rural Health Care Revolution, 1968-1981, Wesleyan University, the Honors College Thesis, 2008.

14. Li Haihong, Chijiaoyisheng" yu Zhongguo xiangtu shehui yanjiu: yi Henansheng weili (Research on "Barefoot Doctors" and Chinese Rural Society: Taking Henan Province as an example), op. cit;; Sidney White, "From 'Barefoot Doctor' to 'Village Doctor': A Case Study of Health Care Transformation in Socialist China," Human Organization, Vol. 57, No. 4, pp. 480-490; The life expectancy of the Chinese population increased from 35 in 1949 to 68 in 1976, and the rural CMS and Barefoot Doctor system contributed to this increase. Li Haihong, "Chijiaoyisheng" yu Zhongguo xiangtu shehui yanjiu: yi Henansheng weili (Research on "Barefoot Doctors" and Chinese Rural Society: Taking Henan Province as an example), op. cit., p. 289. The World Bank called the barefoot doctor system a success in terms of the reduction of infant mortality and increased life expectancy. See Willy De Geyndt, Zhao Xiyan, and Liu Shunli, From Barefoot Doctor to Village Doctor in Rural China, World Bank Technical Paper, No. 187, Washington, DC, The World Bank, 1992.

15. Gail Henderson writes that by the end of the 1970s, "without a comparable rise in per capita income, China transformed its health profile and emerged as one of the few developing nations with a list of major causes of death that closely resembled those of the industrialized countries." Gail Henderson, John Akin, Li Zhiming, Jin Shuigao, Ma Haijiang, and Ge Keyou, "Equity and the Utilization of Health Services: Report of an Eight-Province Survey in China," Social Science \& Medicine, Vol. 39, No. 5, 1994, p. 203.

16. Anna Lora-Wainwright, "Using Local Resources: Barefoot Doctors and Bone Manipulation in Rural Langzhong, Sichuan Province, PRC," Asian Medicine, Vol. 1, No. 2, 2005, pp. 470-489.

17. Fang Xiaoping, Barefoot Doctors and Western Medicine in China, Rochester, NY, University of Rochester Press, 2012. 


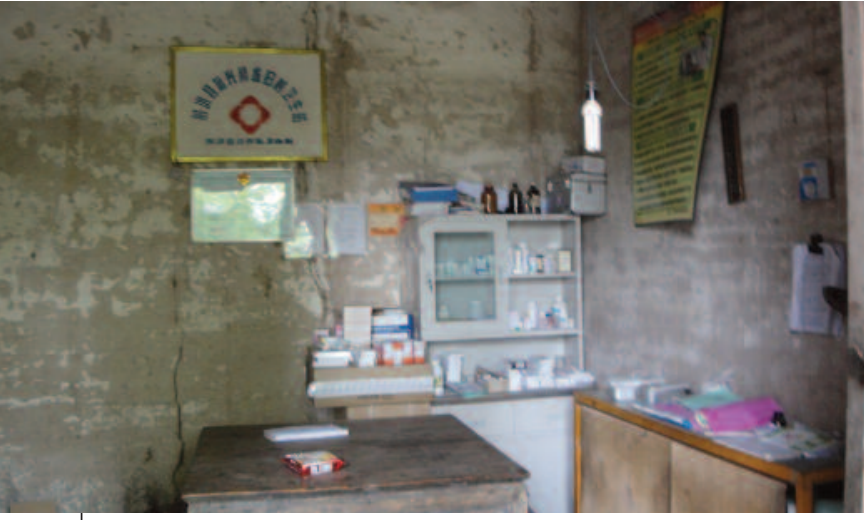

Photo 1 - "Barefoot" Doctor Zhao's clinic at his home () Jiong Tu

The medical team originally occupied a house in the village centre, shared with the village elders' association (laonian xiehui). In 2008, a poor villager's house was destroyed in the earthquake. To help the family, the village committee sold the house occupied by the clinic and the elders' association to the poor family. The committee arranged for the clinic to move to the village school, which had been empty since the school was relocated to the town. But the old school was on the outskirts of the village, and few patients came after the students moved out. When the clinic was burglarised not long afterwards, Doctor Zhao decided to move the clinic back to his own home. When I visited Doctor Zhao at his home in 2012, I could hardly recognise it as a clinic, except for the clinic licence on the wall, a medicine cabinet, and some medicine bottles on the table of the living room (see Photo 1). No trace was left of the collective clinic that had changed to a normal village clinic.

In the post-reform era, many collective clinics in rural China experienced similar fates, being sold to individuals, contracted to former barefoot doctors, or silently disappearing. Records document the privatisation of a large percentage of local clinics during this period. (18) In Riverside County, many village clinics turned from collectively-owned to private overnight in the 1980s, while some lasted until the 1990s but became increasingly privatised. Lost along with the collective clinics was the material and space manifestation of "state" care in the life of ordinary villagers, and the symbolic locus of connection between individual villagers and the socialist collective. ${ }^{(19)}$

\section{From "barefoot doctors" to "village doctors": Self- transformation and professionalization in post-Mao China}

The disappearance of collective clinics in rural China was accompanied by the loss of rural health professionals. Barefoot doctors used to get work points and cash subsidies from the collective production brigade. They generally had a better social and economic status in the rural community. ${ }^{(20)}$ When the collective production system was replaced by the household production system, these doctors could no longer get work points or subsidies. Although in some places, villagers continued to contribute to the income of barefoot doctors collectively, in many other places (most villages in Riverside County), individual villagers were not willing to collectively contribute to doctors' income. Most barefoot doctors had to support themselves by charging patients privately according to the services they provided. Besides that, the private production system put new requirements on these doctors to cultivate their own fields. In the collective production system, barefoot doctors could use their medical work as a substitute for farm work, but now every family had to work their own plots. The farm work to some extent reduced the time and energy these doctors had to practice medicine. Furthermore, in the 1980s the private income of ordinary farmers increased overall. In many villages, barefoot doctors enjoyed no advantage in terms of income, so there was little incentive to stay on as a barefoot doctor. Some doctors began to abandon their medical work. Nationwide, the number of barefoot doctors declined from more than 1.5 million in 1975 to just over 1.2 million in 1983. (21)

Furthermore, medical modernisation put new requirements on barefoot doctors, who were required to update their skills. Most barefoot doctors had no institutional education or qualifications. In the post-reform era, they were subjected to evaluations of their "qualifications" and the "modernity" of their knowledge and skills. In October 1979, the State Council proposed holding examinations to certify barefoot doctors. (22) Barefoot doctors nationwide were required to take the certification examinations in the years that followed. (23) By 1985, the state required all rural health professionals to take the exam; those who passed the exam would be awarded a "village doctor" (xiangcun yisheng) certificate with intermediate professional title, and those who failed or didn't take the exam would be called "primary health workers" (weishengyuan) with a primary professional title. (24) The local authorities of Riverside County also held exams for rural health professionals. Local records show that through an examination in 1983, 367 medical practitioners became licensed "village doctors," and 1,201 professionals received the certificate of "primary health worker" (the total numbers of rural health professionals in 1977 was 1,868 barefoot doctors and 4,880 health workers). ${ }^{(25)}$ Nationwide, among the remaining 1.2 million barefoot doctors, only about half $(640,000)$ passed the exam and obtained the "village doctor" certificate by 1985. ${ }^{(26)}$ The evaluations and tests became

18. Jane Duckett, "Local Governance, Health Finance, and Changing Patterns of Inequality in Access to Health Services," in Vivienne Shue and Christine Wong (eds), Paying for Progress in China: Public Finance, Human Welfare, and Changing Patterns of Inequality, London, Routledge, 2007, pp. 4668; Gail Henderson et al., "Equity and the Utilization of Health Services Report of an Eight-Province Survey in China," art. cit.

19. Although the state did not finance the rural CMS, the collective clinics, and the barefoot doctor system directly, it effectively mobilised the system (such as sending doctors from the urban areas to train doctors in the rural areas) and organisations at the grassroots level (such as the commune and the brigade) to support the CMS and barefoot doctors. Collective clinics and barefoot doctors become a symbol of the socialist collective and the state in rural communities through providing basic health care, taking on public health work, and implementing state policies such as population planning and birth control.

20. Yang Nianqun, "Memories of the Barefoot Doctor System," in Everett Zhang, Arthur Kleinman, and Tu Weiming (eds), Governance of Life in Chinese Moral Experience: The Quest for an Adequate Life, London, Routledge, 2011, pp. 131-145. Xu Sanchun, Qing yilai de xiangcun yiliao zhidu (The medical system of the Chinese countryside since the Qing Dynasty), Doctoral Dissertation, Nankai University, 2012.

21. Li Decheng, Chuangzao yu chonggou: jitihuashiqi nongcun hezuo yiliao zhidu he chijiao yisheng xianxiang yanjiu (Creation and Restructuring: Research on the rural collective medical scheme in the collective era and the barefoot doctor phenomenon), Beijing, China Book Press, 2013, p. 166. Not only barefoot doctors, but also other health professionals serving the rural areas during the collective era also declined dramatically in number. It is estimated that there were an additional 3.7 million health aides in 1970, but the number declined to roughly two million by 1981. Judith Banister, China's Changing Population, Stanford, Stanford University Press, 1987.

22. Fang Xiaoping, "Barefoot Doctors and the Provision of Rural Health Care," in Bridie Andrews and Mary Brown Bullock (eds), Medical Transitions in Twentieth-century China, Indiana University Press, 2014, pp. 267-282

23. Marilynn M. Rosenthal and Jay R. Greiner "The Barefoot Doctors of China: From Political Creation to Professionalization," Human Organization, Vol. 41, No. 4, 1982, pp. 330-341.

24. Li Decheng, Chuangzao yu chonggou: jitihuashiqi nongcun hezuo yiliao zhidu he chijiao yisheng xianxiang yanjiu (Creation and Restructuring: Research on the rural collective medical scheme in the collective era and the barefoot doctor phenomenon), op. cit., p. 166

25. Riverside yiyaozhi (Medical Gazetteer of Riverside County), op. cit.

26. Li Decheng, Chuangzao yu chonggou: jitihuashiqi nongcun hezuo yiliao zhidu he chijiao yisheng xianxiang yanjiu (Creation and Restructuring: Research on the rural collective medical scheme in the collective era and the barefoot doctor phenomenon), op. cit., p. 166 
a process of selection, and only those who "qualified" were allowed to continue medical practice in the rural areas. Hence, in the 1980s and 90s, more former barefoot doctors started to practice medicine privately without a licence or gave up medical practice.

In the 1990s and 2000s, more regulations and administrative rules about "village doctors" were released by the central and local level governments to further regulate village doctors' qualifications and medical practices. ${ }^{(27)}$ Most of the former barefoot doctors who transformed into village doctors and continued medical practice experienced a professionalization process by constantly updating themselves with new knowledge and skills. They took further training, worked towards gaining new diplomas and certificates, and passed various assessments in order to become licensed physicians. Doctor Wei showed me his six certificates (see Photo 2): the "barefoot doctor" certificate from the 70s; the primary professional qualification certificate and village doctor certificate from the 80s; and the village doctor practice certificate, the physician qualification certificate, and the physician practice certificate from the 90 s. Some village doctors also gained a secondary medical qualification and other certificates. These certificates record and trace a village doctor's professional life from barefoot doctor to registered physician, and document an individual doctor's efforts to transform him- or herself into a modern and more qualified doctor.

\section{Village doctors' argument for payment, pension, and status}

In the post-reform era, many former barefoot doctors became village doctors, but "village doctors" in rural areas are actually a diversified group. (28) They include former barefoot doctors who are now between 50 and 80 years old; village doctors who began practicing medicine in the post-reform era (some of them the sons and daughters of former barefoot doctors $\left.{ }^{(29)}\right)$; and former township/commune hospital professionals who took on the role of village doctors after their hospitals dissolved in the 1980s and 90s. The term "village doctors" in this section still focuses on the group of former barefoot doctors who continued medical practice in the rural areas after the changes in the 1980s and 90s, although some of their situations have been experienced by all village doctors.

\section{Economic considerations and moral responsibility}

In order to support themselves, former barefoot doctors (now village doctors) have increasingly become private entrepreneurs, charging patients according to the services provided. They have also gradually shifted from public health and preventive work to curative work, changing from cheap basic medicine to more expensive and adequate medicine (mixing Western and Chinese medicine), frequently giving IV drips and injections in their treatments, and sometimes even over-prescribing to villagers. ${ }^{(30)}$ In the postreform era, some doctors began to earn more than in the past with improved social and economic conditions. However, this has not been the situation for all former barefoot doctors.

The rural areas of Riverside County face the problem of a dwindling and aging population. Since the end of the 1990s, it has increasingly become a case of the "old" serving the "old": a group of aging village doctors have been left to serve elderly "left-behinds" in the village. The young and middle-aged have migrated to the city or coastal areas to work. Those left behind are mainly children and the elderly, who need health care more

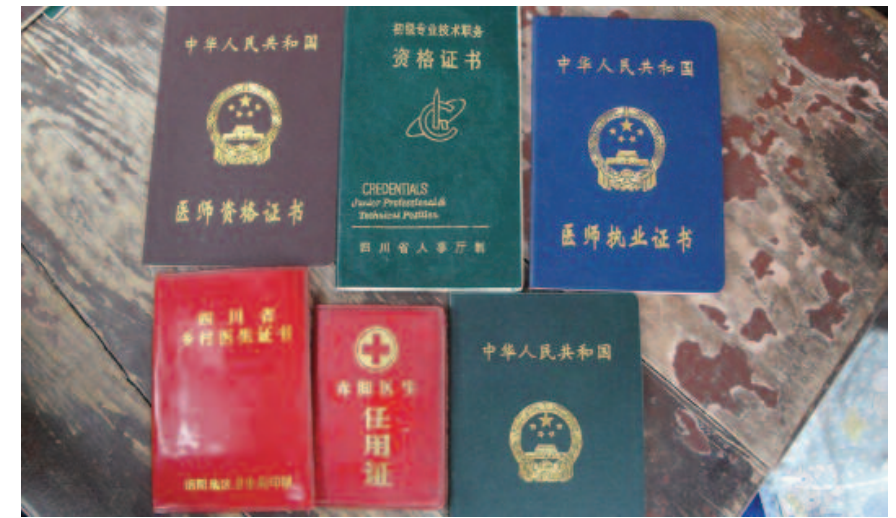

Photo 2 - From barefoot doctor to licensed physician: A village doctor's certificates $\odot$ jiong Tu

than others, but there is a shortage of health professionals in the rural areas. Young doctors do not want to stay in the "undesirable" villages. Middle-aged doctors with heavy burdens to sustain their families are likely to move their clinics to the town or city. Elderly doctors, many of whom are former barefoot doctors, uphold their responsibility to their community and work on meagre incomes, but the number of these doctors is decreasing. Some villages no longer have a doctor once their old doctor passes away. Doctor Yao's story shows the acute situation in the rural area:

Fifty-eight-year-old Doctor Yao has been a village doctor since the 1970s. A few years ago, the old doctor in the neighbouring village passed away, leaving no one to continue medical work there. At the villagers' request, Doctor Yao began to work in two villages: in the morning he saw patients in his village, and then after lunch he drove his motorbike to the neighbouring village for the other half day. In 2004, Doctor Yao's family moved to the city, and he kept driving back to the two villages from the city every day. The muddy rural road made it a long trip, especially on rainy days. In 2007, roads in the rural areas of Riverside County were rebuilt, and Doctor Yao began to move more efficiently between the city and the villages. However, his income as a village doctor declined significantly, since fewer people resided in the villages. The official population of the two villages DoctorYao served was around 1,600, but only half of the population actually resided in the two villages. The new health care reform launched in 2009 made the situation even worse. With the new cooperative medical insurance, more peasants obtained health care at the township and county hospitals, where their medical bills would

27. For instance, the Practicing Physician Law (zhiye yishi fa) released in 1999 and the Regulations on Village Doctors' Practice (xiangcun yisheng congye guanli tiaoli) released in 2003, all regulate the qualifications and medical practices of village doctors.

28. By the end of 1999, there were more than one million village doctors. See Ying Huang and Zhang Kaining, "Xiangcun yisheng de yanbian yu jiceng nongcun yiliao weisheng fuwu yanjiu" (Study of the transformation of village doctors and rural health services), in Zhang Kaining, Wen Yiqun, and Liang Ping (eds), Cong chijiao yisheng dao xiangcun yisheng (From Barefoot Doctors to Village Doctors), Kunming, Yunnan Renmin chubanshe, 2002, p 335.

29. Ying Huang and Zhang Kaining, "Xiangcun yisheng shixi xianxiang dui nongcun jiceng weisheng fuwu zhiliang yingxiang tanxi" (Impact of village doctors' hereditary phenomenon on the quality of rural health services), in Zhang Kaining, Wen Yiqun, and Liang Ping (eds), Cong chijiao yisheng dao xiangcun yisheng (From Barefoot Doctors to Village Doctors), op. cit., pp. 363-371.

30. Also see Willy De Geyndt, Zhao Xiyan, and Liu Shunli, From Barefoot Doctor to Village Doctor in Rural China, op. cit., p. 11; Li Haihong, Chijiaoyisheng" yu Zhongguo xiangtu shehui yanjiu: yi Henansheng weili (Research on "Barefoot Doctors" and Chinese Rural Society: Taking Henan Province as an example), op. cit., p. 274. 
be partly covered by insurance. In the past Doctor Yao saw more than 50 patients a day, but now he had only around 25 patients a day. In order to supplement the loss, in 2011 he began helping at a relative's clinic in the city. He worked in the city in the early morning, drove to his village in mid-morning and worked until lunch time, and then after lunch he drove to the neighbouring village and worked there until $5 \mathrm{pm}$. Then he drove back to the city and worked at his relative's clinic for several hours in the evening.

Doctor Yao was not alone in this situation. Many village doctors I met in Riverside County have had to develop multiple businesses to increase their incomes: opening a grocery store next door to the clinic, doing farm work, selling commercial insurance, selling fertiliser, etc. In one interview, village doctor Zhao commented about another village doctor's work: "What has he done? Farm fish, operate a mill, sell pesticide, treat people, treat pigs [animals], and finally sell insurance. These village doctors, few practice medicine seriously nowadays. Patients are fewer, and seeing one or two patients a day can hardly support a family." Doctor Zhao was worried that these sideline activities would draw village doctors away from their medical work, yet he acknowledged the situation of being a village doctor who could not "support a family."

More economic pressures came from the local authorities. In the 1990s, local village doctors were asked to pay various fees and taxes by local administrative agencies. Many experienced great difficulties in their medical work. Some doctors then changed their private clinics into public-oriented village clinics. The changes required them to take on some public health and preventative care work without or with only limited government subsidy. ${ }^{(31)}$ In exchange they could get exemption from some taxes and fees. The outbreak of SARS in 2003 was a time when the state mobilised village doctors to "fight" against the disease without much compensation. Village Doctor Yao recalled his and his colleagues' experiences during that period:

Every person who came back [home from other areas] had to be registered and followed up by us... As Doctor Ma [in another village] said, the peasants did not follow [our] guidance [after coming back] and went to work in the paddy fields, and we even had to take off our shoes to check their body temperatures in the paddy fields, or climbed up the hill to monitor their situation... It just so happened that our village had a villager who came back from Yunnan Province and caught a cold on the way. His temperature reached 38.9 degrees with a constant cough. I called the health office, and they asked me to diagnose and monitor him... I had to make contact with this patient every day. It was really scary; [by then] many people had died, and we were on the front-line... My records of the SARS period are still here.

After several years, Dr.Yao's notebooks had yellowed, but his handwriting on the cover was still clear: "Promote Chinese medical ethics, help and save human beings, unite the people, conquer SARS." It was a slogan he used to encourage himself to work under dangerous circumstances. He showed me page by page that recorded which villager had come back to the village on which day and what examination he had carried out on them. However, after all this hard work, he received nothing but less than 100 yuan as a subsidy from the local authorities for the telephone bill he racked up reporting the progress of the epidemic to the township health office. It was the same for other village doctors in Riverside County, most of whom were "only left with a (white) mask as a souvenir."

Facing financial needs, these doctors have to make money from local patients, which puts them in a moral dilemma. Some such as Doctor Yao resolve this dilemma by working in multiple sites: opening a clinic in the town or city (to earn more) while maintaining a clinic in the village and visiting villagers when they are called. "If dozens of patients are left in the village without care, it will become a serious social problem," 58-year-old DoctorYao stated. The left-behind elderly and children in his village depend heavily on his service. Pointing to the hill opposite his clinic, Doctor Yao told me that on several occasions he had run from his clinic to the top of the hill like a crazy man within several minutes in order to save unconscious elderly or children who lived on the hill. Decades of work in the rural areas have convinced him of the importance of village doctors for left-behind villagers who otherwise would not get immediate help. In another village, Doctor Li, in his 50s, expressed similar thoughts: "We have dealt with peasants for our whole lives, and we have affection for them. Many old people have chronic illnesses such as asthma, and they can't walk to my clinic. Some have grandchildren to take care of at home, and some keep livestock in the yard that might be stolen if left unattended. I always go to treat them in their homes." These former barefoot doctors exhibit a sense of responsibility to their fellow villagers and to the community they have always served.

\section{Village doctors in the new health care reform: "work needs payment"}

Village doctors' persistent sense of responsibility towards their fellow villagers does not mean they would continue to work like "barefoot doctors" of the past.

Since the early 2000s, China has been implementing a new round of health care reforms in an attempt to reverse the market character of earlier trajectories. The outbreak of SARS in 2003, the re-emergence of some infectious diseases, and the presence of new epidemiological threats such as HIV/AIDS exposed the problems of a Chinese health care system that neglected public health and primary and preventive care. Meanwhile, chronic diseases have already become the major disease burden as the population ages. ${ }^{(32)}$ The change in population structure and disease patterns has spurred renewed interest in primary and community care. The state began to rebuild a New Rural Cooperative Medical System and the three-tiered health care network (county-township-village) with an emphasis on primary and community health care.

Unlike the former CMS that was mainly funded by the rural collectives (in other words, peasants themselves), the new CMS is funded collectively by the central government, local levels of government, and the peasants. Furthermore, organising and managing the new CMS has become part of the government's everyday work. Hence, the rebuilding of CMS has raised new hopes among former barefoot doctors that they will be incorporated into

31. Since the 1980 s, state investment in public health has greatly declined. Many village doctors have ceased to provide public health and preventive health services for which they are not compensated. See Huang Yanzhong, Governing Health in Contemporary China, New York, Routledge, 2013. In the 1990s, in order to get exemptions from some taxes and fees, village doctors began to once again take on some public health work.

32. Winnie Chi-Man Yip, William C. Hsiao, Qingyue Meng, Wen Chen, and Xiaoming Sun, "Realignment of Incentives for Health-care Providers in China," The Lancet, Vol. 375, No. 9720, 2010, pp. 11201130. 
the public healthcare sector. However, unlike the former CMS, which incorporated barefoot doctors as its main executors, the new CMS, focusing on relieving patients' burden of serious illnesses (most of which are treated in public hospitals), has little to do with village doctors, who mainly treat minor and common diseases. Furthermore, the new CMS attracts more peasants to township and county hospitals, where their medical bills are partly covered by insurance, thereby further reducing patient numbers for village doctors. Village doctors are still excluded and marginalised from the public healthcare sector.

In the collective era, barefoot doctors undertook the dual tasks of healing and public health. Under the new health care reform, local health authorities continue to ask village doctors to fulfil their "responsibility and duty" (zeren he yiwu) in performing public health tasks. Yet, village doctors are unwilling to work as "barefoot doctors" did in the past, and have begun to refuse to take on "voluntary" work and have started requesting payment for their labour. Later when the new CMS allocated some funding for outpatient care, village doctors began to get involved in the public healthcare system by delivering outpatient care. As the new health care reform progresses, the state has also begun to subsidise the public health work that village doctors carry out, but they receive only hundreds or a few thousand yuan per year, depending on their performance in fulfilling the allocated tasks. Village doctors are subject to a set of audits and evaluations, which give them numeric measurements according to the amount of public health work they have carried out, the number of health checks they have done, how many forms they have filled out, the number of records they have written, etc. (see Photo 3). In 2011, the allocated subsidy for each local village clinic was 3,000 yuan. Yet the amount was subject to deductions by local health authorities depending on an evaluation of the village doctor's ability to meet work targets. Most village doctors I met received only 1,000 to just over 2,000 yuan after those deductions. Due to the low subsidy and steep deductions by local administrative authorities, village doctors view this new public health work as "unprofitable" tasks. Public health work is interpreted by village doctors as requiring them to "voluntarily and selflessly contribute." Many resist performing these tasks and react with counter-strategies such as faking records.

Since 2011, local village doctors have also been required to adopt the Basic Pharmaceutical Catalogue (jiben yaowu mulu), prescribing only pharmaceuticals in the catalogue at zero profit. The adoption of the Basic Pharmaceutical Catalogue in the new health care reform aims to change the situation of doctors and medical institutions making a profit from pharmaceutical prescription. This threatens village doctors' main source of income since market reform. Village doctors noted various problems with the Basic Pharmaceutical Catalogue: the catalogue is not comprehensive enough to meet daily medical needs, some drugs on the list are even more expensive than the market price, some drugs are from brands they've never heard of, and so on.

Village doctors also employ market rationales to reject carrying out these "unprofitable" tasks and "unreasonable" policies. "[The government] asks us to work, but doesn't give us subsistence. It's just like 'forcing the horse to run without feeding it'; it won't work," said an old village doctor. Many regard their labour as underpaid and undervalued in the new health care reform. Without sufficient operating funds, village doctors still focus on curative work and selling medicine outside the Basic Pharmaceutical Catalogue to pull in revenue. These village doctors, who have been liberated in the market for decades, adopt the work-reward mentality to argue for their

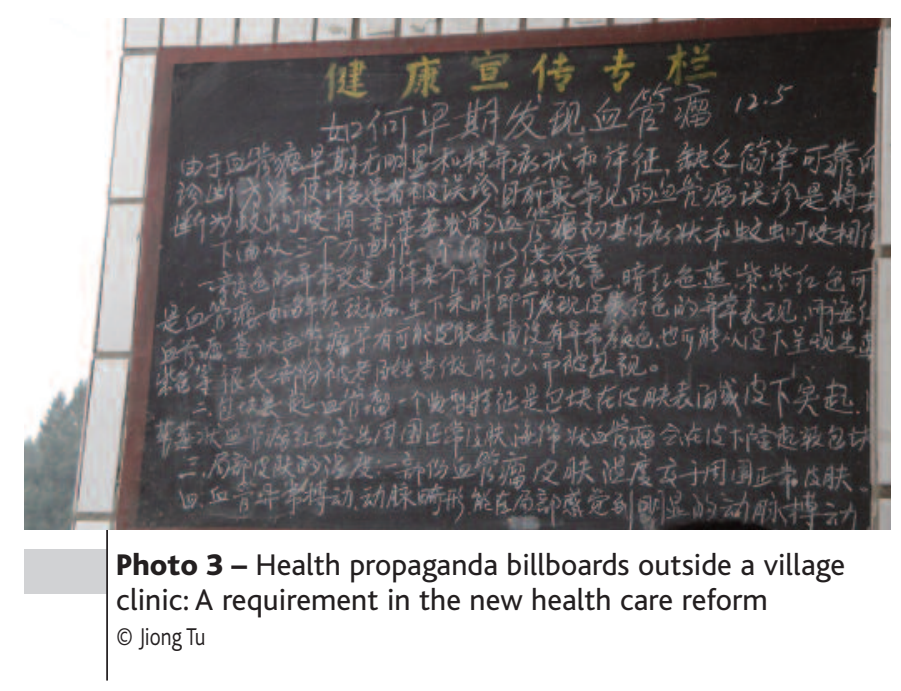

payment from the government, ${ }^{(33)}$ and resist being shaped by the socialist discourse of "selfless dedication" and by the new audit system. For village doctors, health care has changed from a political and moral mission to a source of economic revenue and a terrain to argue for their compensation. Over the years, the subsidies for village doctors have gradually increased. As of 2016, village doctors in Riverside County can get up to 20,000 yuan a year for fulfilling all public health work. However, what most doctors hoped for was the chance to be formally enrolled in the public healthcare system, to get a monthly salary from the state, and enjoy a secure life after retirement. Doctor Yao told me that for him and his colleagues, "A salary of merely 1,000 yuan per month, plus subsidies for public health work, was sufficient." Yet, under the new health care reform, village doctors are still outside the public healthcare workforce, even though the state has begun to subsidise them. Many elderly village doctors have fewer opportunities and less energy to earn enough money to support themselves in the market and in the new reforms. Every year, increasing numbers of elderly village doctors become too old to continue medical practice. These doctors have urgent concerns about their livelihood in old age, and many have begun to demand pensions.

\section{The pension argument and action}

The old barefoot doctors generally resorted to their past contributions to argue for compensation today. In the letter above, they listed the work they had done at length. They highlighted their selfless contributions under difficult working conditions. Some even traced their contribution back to the time before they became "barefoot doctors." The letters and autobiographies written by the former barefoot doctors were full of strong emotional words: "broken-hearted," "disappointed and depressed," "lonely and desolate," and "driven to despair," etc. These barefoot doctors regarded themselves as the most unfortunate. When they were young and able, they followed socialist guidance to serve the people without making money for themselves. Now they are old and will lose their working ability soon, but they do not have pensions to secure their livelihood. They felt they should be compensated for their past contributions, but found they were ignored

33. This new market "work-reward" logic is somewhat different from the "work point" system adopted in the socialist period. "Work points" were a very crude evaluation. In Riverside County, a barefoot doctor' daily work was counted as 1.2 times an ordinary villager's daily work points, but they needed to take on a great deal of work that wasn't evaluated. The market "work-reward" logic tends to put everything into evaluation, and village doctors have clear ideas about the value of their labour and specific demands for the amount of monetary rewards. 
by recent reforms. "I have worked more than four decades. Even if you deny my achievement, I deserve some recognition for my hard work; if I am given no credit for hard work, at least I should be rewarded for being exhausted" (meiyou gonglao you kulao, meiyou kulao you pilao), Doctor Wei, in his late 60 s, said resentfully. His words expressed the collective sentiments shared by many former barefoot doctors, who felt lost and forgotten, and felt they did not get decent credit for what they had done and were doing. "We have contributed to the country for decades, we are old, we need to eat," 76-year-old Doctor Li said. By using their past experience of hard work and their current poor livelihood, village doctors have formed a moral economy claim to subsistence. "We are pushed to the edge of life. The Communist Party says the old will get care (lao you suo yang), but now we are not cared for (laole mei de yang)," Doctor Zhao said resentfully. Ironies abound in his words, which echo the perspective and experience typical of the older generation. These old doctors watch news, share information with one another, and are extremely knowledgeable about state policies. Recent state efforts to rebuild social safety nets have provided them a new terrain to articulate their claims. "At this year's national congress, premier Wen Jiabao said even vagrants would be given food to eat, so how could we not?" Doctor Lian asked. Premier Wen is popular among the general public, with the media always showing his benevolent concern for people at the bottom rungs of society. The central government positions itself as a protector of the people at the bottom. Reciting the premier's words and the party's proposal endowed these elderly doctors with greater legitimacy to seek their entitlement for subsistence.

Yet in the local government, "Those people [officials] just think about making money; they deny our contribution for all those years. We have been completely forgotten," Doctor Li complained. The words reflected local village doctors' shared concern that local governments focus on economic development while ignoring their welfare. By comparing the central government's good proposal with the dismal local situation, these old doctors imply that the local government has failed to take on its duty and has not lived up to the ideals in the media representations. While intensely resentful, they don't show subversive attitudes towards the central government and the party. Rather, their letter praises the good policies and positive changes the party had established in the rural areas in the past few years, and calls for this "grace" to be bestowed on them as well.

Facing the dismal situation today, village doctors become sentimental of the past. Doctor Yao recounted with great nostalgia:

In the 70s, peasants took medicine for free and only paid 4 pence as a diagnosing fee. Doctors' daily work was calculated as 1.2 peasant working days; if a villager earned 100 work credits a day, we earned 120 credits, and on top of that, we received a 6 yuan subsidy every month. Besides, we were treated at the same level as village cadres. We felt respected and had a sense of honour as doctors. Now we feel insecure and unsure about our future.

Most old doctors I interviewed could clearly recall their incomes in the collective era, when they got not only higher work points, but also additional cash income. In addition, they enjoyed a prestigious status in the local community and were respected by villagers, and some even regarded their status as equal to village cadres. "Even the cadres needed to come to us [when they were sick]," many old doctors said proudly. These doctors carefully preserved the symbolic rewards (flags, certificate of merits, medals, etc.) they received in the collective era, which they frequently took out in my pres- ence. However, even this symbolic recognition has vanished now. Disappointed with their loss of status, recognition, and benefits, the elderly doctors embrace a narrative of the past to reinforce their legitimate moral claim for "compensation" today.

The old doctors had great expectations that the new health care reform would solve their long-standing pension issue. However, as the reform progressed, they found that nothing changed and felt even more disappointed. Since 2000, village teachers, veterinarians, and other professional groups who took public posts in rural areas of Riverside County during the collective era have received pensions one by one. Yet, the problem of village doctors' pensions has yet to be resolved. Village doctors feel they've been left behind by the new developments and have become increasingly upset. "Doctors who treat pigs (animals) are much better off now than we who treat human beings." I heard these words repeatedly from almost every village doctor I encountered. It highlighted the difference between other pension-receiving groups and village doctors' own dismal circumstances. Regarding themselves as the "first-class peasants" in the collective, these doctors now called themselves "second-class citizens" who weren't given equal treatment by the government.

Since the 2000s, local village doctors have increasingly put their pension claims into action. They've written autobiographies of their career lives, sent complaint letters to authorities, sought out media attention, visited government offices, and organised petitions. Meeting with me was another strategy to express their complaints, in hopes that my research could help solve their problems, but hearing the lost generation's lament, I could do little more than lend a sympathetic ear. Their petition letters and autobiographies targeted an imagined high-level official, who they hoped would resolve their issue after reading their materials. However, in reality, they haven't been able to find such a high-level official to submit the petition letter to. Ultimately, they could only write down the name of the county health bureau chief, the highest official they could possibly reach out to. However, their letters did not get them any response. In 2008, local village doctors attempted to organise a collective petition. Doctor Lian and Doctor Zhao were two of the organisers. They recounted to me in detail how they contacted village doctors in the whole county, even village doctors in neighbouring counties, but only a few dozen village doctors came. They gathered in a square in the county capital and planned to march to the county health bureau to pressure bureau leaders to solve their pension issues, but the local authorities learned of their gathering. A government official came to the square with a document about collective actions being prohibited. The official warned them that those organising petitions or protests would be detained. Faced with this dramatic turn, the group of village doctors I met became emotional:

Doctor Lian:We village doctors, we doctors [who have worked] since the 70 s reported our situation to the authorities, but our personal safety couldn't be secured. [We were] not allowed to petition, and gathering was regarded as trouble-making.

Doctor A:They [the local officials] said our action would disturb social stability.

Doctor Zhao: Two years ago, the county released a document stating that whoever organized the petition or protest would be arrested; it had the official seals of five departments.

Doctor B: The radio station has broadcast it.

Doctor C: It has been broadcast on the TV, too...

Doctor Zhao: If we organize a petition, it is an illegal action. They will detain people [involved]. It makes it difficult for us to act. 
Doctor A: Otherwise we would have already gone to [petition in] the provincial capital.

The village doctors were quickly discouraged by the containment measure of local authorities in a period of "tightening" social control before the Beijing Olympics in 2008. Afraid of being accused of "disrupting social order," village doctors quit their petition attempts and withdrew from future collective action, but their resentment did not go away. After the attempt in 2008 , local village doctors continued taking part in small actions. They supported any act that was in accordance with their own interests, piggybacked their pension concerns to other issues relevant to their daily medical practices. When village doctors in a neighbouring town protested against the charging of an unnamed "development fee" by their township health office in 2010, village doctors in Revival Town also signed their names in support of the protest. Over the years, village doctors have continually relayed their issues to any "knowledgeable" person they can reach, have handed their complaint letters to the authorities, have met up in each other's clinics, and have contacted one another through telephone and the internet. Younger village doctors, who have the same worries as the former barefoot doctors about salaries and pensions (albeit not as imminently), have taken their complaints to the internet, posting videos about village doctors' miserable life ${ }^{(34)}$ and creating chat groups for village doctors' to discuss work-related issues, including the pension problem. However, village doctors' actions are generally limited to these fragmented acts.

Village doctors are a divided group with diversified interests and demands, which makes them unable to form a unified action group. Former barefoot doctors who have continued medical practice in the rural areas are the most resentful ones, but aged in their 50 s to 80 s, some are too old and feeble to join in collective action. Village doctors who started their medical practice in the post-reform era are generally younger and do not consider the pension issue as pressing as the older barefoot doctors, although they are also demanding a pension system. Former township/commune hospital professionals, who took on the role of village doctor after their hospitals dissolved in the market era, have fought for their pensions within their own "township hospital professional" group, and argue their interests differently from the barefoot doctors. Even the former barefoot doctor group contains several sub-groups: those who stopped practicing medicine upon the implementation of rural reform in the early 1980s, those who stopped practicing medicine because of poor medical proficiency or low income in the 1980s and 90s, and those who have continued practicing medicine up to now, but face the issue of retirement amidst the recent health care reform. It is the former barefoot doctors who have continue medical practice who still struggle the hardest now, but it has been difficult for them to turn their pension claims into collective action and put real pressure on the local government. After years of struggle, these doctors have yet to see any concrete results. Some old doctors have passed away without getting any compensation.

\section{Village doctors' payment and pension issue}

Payment and pensions for former barefoot doctors are a long-standing issue. In the collective era, these doctors were not on the government payroll but received regular incomes from their production collectives. In the post-reform era, although the central government unequivocally recognises these doctors' payment and pension needs, it has spared itself the burden of remunerating this vast cohort of medical workers. Instead, it delegates the responsibility to individual provinces and local municipal authorities. The central government has issued various "suggestion" documents to local governments to resolve the issue of village doctors' payment and retirement, ${ }^{(35)}$ and central leaders have repeatedly emphasised the importance of securing village doctors' payment and livelihood. (36) Recently, there are two general ways to support village doctors in rural China. In some areas (particularly provinces and municipalities in more developed regions), the local government has begun to incorporate village doctors into the public healthcare sector by giving them formal employee status and a basic salary, ${ }^{(37)}$ and has begun to give elderly village doctors livelihood subsidies or public employee pension insurance. ${ }^{(38)}$ However, in most places, it is hard to adopt similar policies. Resource-strapped and poorer agricultural localities such as Riverside County face difficulties handling these doctors' payments and pensions. In Riverside County, there were 1,868 recorded barefoot doctors by 1977, and even now there are still more than 1,000 former barefoot doctors requesting pension compensation. Without a clear national regulation on pension resolution, and lacking public funding from the higher-level government, the local authorities are not willing or able to shoulder pension responsibilities. Besides, most village doctors' qualifications are still quite low. ${ }^{(39)}$ Less trained and educated, and with low

34. For one video about village doctors' miserable life, see "Xiangcun yisheng de xinsheng" (The voices of village doctors), Youku, http://v.youku.com/v_show/id_XMzkyOTYyNzcy.html (accessed on 27 October 2014)

35. The state has started to recognise the importance of village doctors' services. In August 2013, the National Health and Family Planning Commission issued a "Circular to Further Improve Village Doctors' Pension Policy, Increase Village Doctors' Income, and Insure the Function of Rural Healthcare Service Network." National Health and Family Planning Commission, Jinyibu wanshan xiangcun yisheng yanglao zhengce, tigao xiangcun yisheng daiyu de tongzhi, 2013, www.nhfpc.gov.cn/jws/s3581/201308/ca329d50ec4e4e56af4fb7a5c519d245.shtml\# (accessed on 15 June 2014). In May 2014, the central government released the "Circular on the 2014 Working Tasks to Deepen Health Care Reform," which stated that "policies about village doctors' pension should be implemented, [local governments should] adopt various measures to properly solve elderly village doctors' pensions and difficult livelihoods, and set up a retirement mechanism for village doctors simultaneously." State Council, Guanyu yinfa shenhua yiyao weisheng tizhi gaige 2014 nian zhongdian gongzuo zewu de tongzhi, 2014, www.gov.cn/zhengce/content/201405/28/content_8832.htm, (accessed on 31 May 2014). Yet how these policies will be implemented locally is uncertain. Again in early 2015, the State Council issued "Implementation Opinions on Further Strengthening the Village Doctor Team Building," which includes ensuring proper income for village doctors, and setting up a well-organised pension and retirement policy for elderly village doctors. State Council, Guanyu jinyibu jiaqiang xiangcunyisheng duiwu jianshe de shishiyijian, 2015, www.gov.cn/zhengce/content/2015-03/23/content_9546.htm (accessed on 14 August 2015).

36. See reports such as "Li Keqiang jinshan kanwang Guizhou Dong zhai pinkun hu zi taoyao baosong nianhuo" (Premier Li Keqiang visited poor families in Dong Village of the mountain area of Guizhou Province, delivering New Year supplies at his own expense), Renmin wang, 14 February 2015, http://politics.people.com.cn/n/2015/0214/c1024-26566145.html (accessed on 15 February 2015). In this visit, he reassured village doctors in this village about their livelihood and subsidies.

37. For example, Guangdong Province; see General Administrative Office of The People's Covernment of Guangdong Province, Guangdongsheng jinyibu jiaqiang xiangcunyisheng duiwu jianshe shishifangan de tongzhi (Implementation plan of Guangdong Province on further strengthening village doctors' team), 2015, http://zwgk.gd.gov.cn/006939748/201509/t20150924_621281.html (accessed on 3 March 2016).

38. For instance, Guangdong Province began to give livelihood subsidies to these former "barefoot doctors" and midwives who served in the rural areas during the collective era. "Guangdong li gang 'chijiao' yisheng ke ling buzhu mei yue bu 700-900 yuan" ("Retired" barefoot doctors in Cuangdong could get livelihood subsidy at 700-900 yuan a month), Renmin wang, 17 January 2013, http://society.people.com.cn/n/2013/0117/c136657-20238249.html (accessed on 10 April 2014). In Jiangsu Province, elderly village doctors were given public employee pension insurance. "Guojiaweijiwei: jiang jinyibu wanshan xiangcun yisheng yanglao zhengce" (National Health and Family Planning Commission: Further improve village doctor's pension policy), Renmin wang, 30 November 2013, http://politics.people.com.cn/n/2013/1130/c1001-23702409.html (accessed on 10 April 2014).

39. Research shows that up to $70 \%$ of medical professionals have no qualifications beyond junior high school in poor rural counties in China. See Karen Eggleston, Li Ling, Meng Qingyue, Magnus Lindelow, and Adam Wagstaff, "Health Service Delivery in China: A Literature Review," Health Economics, Vol. 17, No. 2, 2008, pp. 149-165. 
qualifications, many find it difficult to pass the physician examination and therefore cannot be recruited as formal employees of the public sector. Instead, many local governments such as Riverside County contract rural health care and public health services to village doctors, subsidising/paying them according to the allocated tasks they accomplish. ${ }^{(40)}$ Yet this measure has its problems, as shown above: waste of program funds, the withholding of funds by local levels of government, the low subsidies village doctors actually receive, etc. Village doctors in Riverside County are still not having their demands met.

Elderly village doctors have repeatedly visited the health bureau with documents issued by the central government, yet they've been told these were just "suggestions," not mandates. During an interview in early 2012, an official from the county health bureau said:

There are many conflicts in our work, such as the barefoot doctors. They earned their own salaries in the 80s and 90s, but now they are old and cannot earn enough money. Life has become difficult, but the country hasn't given them a pence.

The official granted symbolic and verbal recognition of the former barefoot doctors' pension needs, but felt helpless to solve the problem without funding from the higher-level government.

The payment and pension issue of these former barefoot doctors and current village doctors is related to the rural-urban segregation that has continued in China since the founding of the PRC. The rural-urban divide has led to inequality in health care and other welfare entitlements between rural and urban residents, as well as the inequality of status and entitlements of doctors that serve rural and urban areas. The payment and pension issue of these rural doctors to some extent was concealed in the collective era due to the existence of rural production collectives that shouldered the payment responsibilities and the relatively higher status and income of barefoot doctors in the rural community. However, as market reform has progressed, these doctors could not get payment from any party, and the relative advantages of being a doctor in the rural areas decreased. These doctors are still regarded as "peasants" who have land to support themselves, hence they are not given salaries or pensions by the government. Since 2012 when the national rural pension scheme began to be implemented in Riverside County, local authorities have encouraged village doctors to buy their own pension insurance like other villagers. However, not having received compensation for their past "contributions," the former barefoot doctors rejected this proposal. In the collective era, the barefoot doctors' gradual removal from agricultural labour, their professional knowledge, and specialised work meant that they gradually became a special category of the village community; in the 1980s and 90s, the professionalization process further separated these doctors from their fellow villagers. ${ }^{(41)}$ In my interviews in 2012, these former barefoot doctors generally regarded themselves differently from ordinary peasants and therefore felt that they deserved more than the social security programs to which ordinary villagers are entitled. They compared themselves with village teachers and veterinarians, who took public postings in the collective era but are already receiving pension, and they demanded that the state recognise their professional status and with it their request for pensions. After many years, they are still waiting for the "lucky chance" (jiyuan) to resolve their pension issue. They thought the chance would come after the SARS epidemic in 2003, during the Hu-Wen leadership that began in 2004, after the earth- quake disaster in 2008, and during the new health care reform beginning in 2009. When I finished my fieldwork in Riverside County in 2012, they were still waiting for this "lucky chance" with no immediate hope. ${ }^{(42)}$

\section{Discussion and conclusion: Revaluating the historical experience of barefoot doctors}

The article traces the transition of a group Chinese doctors, their change from barefoot doctors who worked in very difficult conditions in the collective era, to individual doctors in the market era who have struggled with qualification requirements, market competition, and self-support, to the new ambiguous status of village doctors who constitute an important part of the primary health care network but are still marginalised in the health care system.

Barefoot doctors were motivated to work hard and contribute to the health of the peasants since the collective era. Yet in the post-reform era, they were quickly forgotten as the state focused on economic development and the modernisation of the healthcare system. Without income from the rural collective, some barefoot doctors gave up medical practice. The doctors who continued medical practice reinvented themselves as village doctors and had to support themselves by charging private fees. These doctors lack institutional training and qualifications, and have been urged by the government to improve their skills and modernise their medical knowledge. Indeed, these doctors have actively fostered their own transformation by gaining further training and qualifications, working hard to support themselves. Yet it is not possible for every doctor to rapidly adapt to the market. Some who are older, more vulnerable, and less productive have become uncompetitive in the market.

The rebuilding of a new Rural CMS and the three-tiered health care network in recent health care reforms raised new hopes among these doctors that they would be incorporated into the public healthcare sector with a salary from the state and a secure life after retirement. However, as the reforms progressed, they found they were still excluded from the public sector and were marginalised in the health care system. Individual doctors who have been liberated in the market for decades have adopted the work-reward mentality to argue for their interests. They have showed resistance to the requirements put on them under the new health care reforms (to take on more public health work and to carry out reform policies), and have demanded sufficient payment for their services in the rural areas.

Since the 2000s, many former barefoot doctors have approached retirement age. Facing the imminent loss of their ability to work, they began to demand a pension. These doctors iterated their past contribution, drew on their current difficult livelihood and old age, and employed moral rhetoric of both the socialist ideals of securing people's livelihood and the work-reward logic of the market to argue for proper salaries and pensions. Barefoot doctors conceptualise their arguments in terms of subsistence. They refer to "need" - the "need to eat" (yao chifan) - to show the moral imperative

40. See Office of the State Council, Guowuyuan bangongting guanyu jianquan jiceng yiliao weisheng jigou buchang jizhi de yijian (Opinions on improving the compensation mechanism for medical institutions at the bottom), 2010, www.nhfpc.gov.cn/tigs/s8340/201309/266f2b428c974c 16a00222fac6f0b3a8.shtml (accessed on 22 May 2016).

41. Fang Xiaoping, "Barefoot Doctors and the Provision of Rural Health Care," art. cit., p. 279.

42. In 2016, these elderly doctors in Riverside County still hadn't resolved their pension issue, but as the subsidies for public health work have increased, the younger village doctors (less than 60s) have become less resentful, although they still expect retirement and a secured pension. 
of pensions in old age. They use their contribution and hardship during the collective era and the post-reform era to demonstrate that they "deserve" a pension when they are old. And they display their medical practice now to show they have already made the best effort to be responsible for themselves, but face the imminent loss of their ability to work. They rally around policy slogans promulgated by the central government for securing people's livelihood, but local health officials encourage them to buy rural pension insurance for themselves. The former barefoot doctors expect more than the pension program to which ordinary villagers are entitled. Not having received compensation for their past "contributions," they do not agree with this proposal. The feeling of being abandoned by the reforms has entrenched their sense of being in a post-socialist world. Their loss mainly comes from comparing their past with their current situation, themselves with other groups (such as village teachers and veterinarians who already receive pensions), and the actual situation with their higher expectations. The elderly doctors want the state to recognise their decades of contribution, their for- mer "barefoot doctor" identity, and the corresponding benefits and compensation they deserve. However, the authorities have not responded to their demands, and their collective action has even been repressed by local governments.

1 Jiong Tu is an assistant professor at the Department of Sociology and Social Work, School of Sociology and Anthropology, Centre for Medical Humanities, Zhongshan School of Medicine, Sun Yat-Sen University.

School of Sociology and Anthropology, Sun Yat-sen University, 135 West Xingang Road, Guangzhou, Guangdong Province, China 510275 (tujiongnk@gmail.com).

Manuscript received on 12 September 2016.

Accepted on 1 November 2016. 